Gut and Liver, Vol. 5, No. 2, June 2011, pp. 133-142

REVIEW

\title{
Biliary Strictures after Liver Transplantation
}

\author{
Choong Heon Ryu and Sung Koo Lee \\ Department of Gastroenterology, Asan Medical Center, University of Ulsan College of Medicine, Seoul, Korea
}

Biliary strictures are one of the most common complications following liver transplantation, representing an important cause of morbidity and mortality in transplant recipients. The reported incidence of biliary stricture is $5 \%$ to $15 \%$ following deceased donor liver transplantations and $28 \%$ to $32 \%$ following living donor liver transplantations. Bile duct strictures following liver transplantation are easily and conveniently classified as anastomotic strictures (AS) or non-anastomotic strictures (NAS). NAS are characterized by a far less favorable response to endoscopic management, higher recurrence rates, graft loss and the need for retransplantation. Current endoscopic strategies to correct biliary strictures following liver transplantation include repeated balloon dilatations and the placement of multiple side-by-side plastic stents. Endoscopic balloon dilatation with stent placement is successful in the majority of AS patients. In patients for whom gaining biliary access is technically difficult, a combined endoscopic and percutaneous/surgical approach proves quite useful. Future directions, including novel endoscopic retrograde cholangiopancreatography techniques, advanced endoscopy, and improved stents could allow for a decreased number of interventions, increased intervals before retreatment, and decreased reliance on percutaneous and surgical modalities. The aim of this review is to detail the present status of endoscopy in the diagnosis, treatment, outcome, and future directions of biliary strictures related to orthotopic liver transplantation from the viewpoint of a clinical gastroenterologists. (Gut Liver 2011;5:133-142)

Key Words: Liver transplantation; Anastomotic strictures; Bile duct diseases; Endoscopic retrograde cholangiopancreatography

\section{INTRODUCTION}

Liver transplantation is a life saving procedure for patients with chronic end-stage liver disease and acute liver failure when there are no available medical and surgical treatment. ${ }^{1-3}$ Since Thomas Starzl performed the first liver transplantation in 1963, there have been significant advances in all aspects of organ selection, retrieval, preservation, and implantation techniques. Therefore, the overall 1-year survival for adult and pediatric deceased donor liver transplantation (DDLT) is now expected to be in excess of 85\%, with 5- and 10-year survival in excess of $70 \%$ and $60 \%$, respectively. ${ }^{4-7}$ However, complications of the biliary tract remains a common source of morbidity and mortality. Some authors call it "Achilles heel of orthotopic liver transplantation."

Biliary leaks and strictures are the most common biliary complications, but sphincter of Oddi dysfunction, hemobilia, and biliary obstruction from cystic duct mucocele, stones, sludges or casts have also been observed..$^{9-11}$ The rate of bile leaks or strictures at the anastomotic site or cut edge of the transected liver, were reported in 15\% to $60 \%$ of recipients in early, single center reports. ${ }^{12}$ These high rates of post-transplant biliary complications, may point to an inherently sensitive nature of the biliary epithelium to ischemic damage in comparison to hepatocytes and vascular endothelium. ${ }^{13}$

Improving survival of liver transplants, biliary complications also increased in long-term survival patients. These complications not only affect graft survival but also have a major impact on the quality of life for a liver allograft recipient, as they lead to frequent readmission, reoperation, hospital stays, and escalate costs and add to the emotional trauma that patients suffer.

Surgical repair traditionally has been the preferred approach in biliary complication of orthotopic liver transplantation. With advances in therapeutic and diagnostic endoscopy, the nonoperative management of biliary complications has become

\footnotetext{
Correspondence to: Sung Koo Lee

Department of Gastroenterology, Asan Medical Center, University of Ulsan College of Medicine, 86 Asanbyeongwon-gil, Songpa-gu, Seoul 138736, Korea

Tel: +82-2-3010-3180, Fax: +82-2-476-0824, E-mail: sklee@amc.seoul.kr

Received on January 6, 2011. Accepted on February 1, 2011.

pISSN 1976-2283 eISSN 2005-1212 DOI: 10.5009/gnl.2011.5.2.133

@ This is an Open Access article distributed under the terms of the Creative Commons Attribution Non-Commercial License (http://creativecommons.org/licenses/by-nc/3.0) which permits unrestricted non-commercial use, distribution, and reproduction in any medium, provided the original work is properly cited.
} 
standard techniques as the preferred diagnostic and therapeutic modalities.

The aim of this review is to overview a present status of endoscopic role in the diagnosis, treatment, outcome, and future directions of biliary stricture related to orthotopic liver transplantation, from the viewpoints on clinical gastroenterologist.

\section{INCIDENCE OF BILIARY STRICTURES}

Studies regarding long-term outcomes after liver transplantation indicate that approximately 5\% to 30\% of recipients will develop biliary complications after transplantation. The most common biliary complications are bile leaks, anastomotic and intrahepatic strictures, stones, and ampullary dysfunction. Leaks predominate in the early posttransplant period ( $<3$ months). Stricture formation typically develops gradually over time. Biliary strictures are the most frequent type of late biliary complication (>3 months) and are typically due to ischemia/reperfusion injury, vascular insufficiency, or fibrotic healing caused by improper technique. ${ }^{14-17}$

Although the strictures can present at any time after the surgery, the mean interval at the time of presentation is 5 to 8 months after orthotopic liver transplantation and the majority present within 1 year, ${ }^{17-22}$ but recent studies suggest that their prevalence continue to increase with the time after transplantation. $^{23}$

\section{CLASSIFICATION OF BILIARY STRICTURES}

Bile duct strictures after liver transplantation are easily and conveniently classified as anastomotic strictures (AS) and nonanastomotic strictures (NAS). The clinical outcomes of the 2 types are markedly different, rendering their distinction clinically relevant.

NAS account for $10 \%$ to $25 \%$ of all stricture complications after orthotopic liver transplantation, with an incidence of $1 \%$ to $19 \%$; these are often multiple, longer and occur earlier than anastomotic strictures. AS, on the other hand, are isolated, are localized to the site of the anastomosis, and are short in length. Their reported incidence in the modern literature is $4 \%$ to $9 \%$.

\section{PATHOGENESIS AND RISK FACTORS}

\section{AS}

The underlying basis for AS includes ischemia or fibrosis following a suboptimal surgical technique or a bile leak in the postoperative period. ${ }^{21,23,24}$ Early in the postoperative period, technical issues appear to be the most important: improper surgical techniques, small caliber of the bile ducts, a mismatch in size between the donor and recipient bile ducts, inappropriate suture material, tension at the anastomosis, excessive use of electrocauterization for control of bile duct bleeding, and infec- tion $^{8}$

Later onset anastomotic strictures most likely indicate fibrotic healing arising from ischemia at the end of the donor or recipient bile duct. ${ }^{14-16,21,23-25}$

According to some series of whole organ orthotopic liver transplantation, they are reported to be more common after hepaticojejunostomy than after direct duct-to-duct anastomosis, ${ }^{9,11,26}$ as well as following duct-to-duct anastomosis in non$\mathrm{T}$-tube recipients, as compared to the anastomosis over a Ttube. ${ }^{27-30}$ In right lobe living-donor transplants, the incidence of duct to duct anastomotic strictures has been consistently higher, as compared to recipients of whole liver grafts. ${ }^{31-35}$ This is considered to be related to the blood supply of the anastomosis and often the presence of multiple and small caliber donor ducts.

\section{NAS}

NAS are heterogeneous entities, and on the basis of the etiology, Moench et al. ${ }^{36}$ proposed a classification dividing them into NAS secondary to macroangiopathy and NAS secondary to microangiopathy (preservation injury, prolonged cold and warm ischemia times, donation after cardiac death, and prolonged use of vasopressors in the donor) and immunogenicity (chronic rejection, ABO incompatibility, autoimmune hepatitis, and primary sclerosing cholangitis). Less important and inconsistent are the reported associations with hepatitis $\mathrm{C}$ and cytomegalovirus. $^{11,37,38}$

NAS present earlier than AS, with the mean time to stricture development being 3.3 to 5.9 months. ${ }^{20,37}$ Verdonk et al. ${ }^{39}$ further reported that NAS secondary to ischemic causes presented within 1 year of the transplant, whereas the occurrence after 1 year was more often related to immunological causes as the risk factors.

\section{PRESENTATION}

Patients may be asymptomatic at presentation, with elevations of serum aminotransferases, bilirubin, alkaline phosphatase and/or gamma-glutamyl transferase levels. A high index of suspicion must be maintained, as pain may be absent in the transplant setting because of immunosuppression and hepatic denervation..$^{40-42}$

A recent report of 15 patients highlighted the use of serum bilirubin $>1.5 \mathrm{mg} / \mathrm{dL}$ as a better indirect marker of biliary stasis in living donor liver transplantation (LDLT) than alkaline phosphatase, which is overly sensitive. ${ }^{43}$

\section{DIAGNOSIS}

Initial evaluation should include liver ultrasound (US) with Doppler evaluation of the hepatic vessels. If hepatic artery stenosis or occlusion is suspected on Doppler US, hepatic angiography is usually indicated. Unfortunately, in liver transplant 
patients, abdominal US may not be sufficiently sensitive (sensitivity of $38 \%$ to $66 \%$ ) to detect biliary obstruction. ${ }^{44}$

In addition, the size of the duct has not been found to be a reliable indicator in following up these patients or in accessing the response to the treatment. Furthermore, there is a significant lack of correlation between the ducal dilatation on the ultrasound and the cholangiographic and clinical feature. It is not clear why the donor bile ducts do not respond to distal obstruction by displaying the same degree of proportional dilation as non transplanted livers. ${ }^{43}$ However, It is possible that the presence of variable degrees of fibrosis subsequent to the injury sustained at the time of the perioperative period results in less pliable ducts. ${ }^{45}$

Scintigraphy of the hepatobiliary tract with 99-technetium labeled iminodiacetic acid identifies strictures with 75\% sensitivity and 100\% specificity but a lack of therapeutic benefit limits its clinical use. ${ }^{46,47}$

Magnetic resonance cholangiopancreatography (MRCP), which has a sensitivity and specificity close to $90 \%$ in establishing the diagnosis of biliary strictures. ${ }^{48-50}$ MRCP is currently considered an optimal noninvasive diagnostic tool for the assessment of biliary complications after orthotopic liver transplantation. ${ }^{8}$ Once MRCP expertise becomes more widely available, it should have an even more prominent role in limiting the role of invasive cholangiography for therapeutic purposes. The chief disadvantage is the lack of its therapeutic ability. It can be used as the second step after ultrasound in patients for whom the use of diagnostic endoscopic retrograde cholangiopancreatography (ERCP) or percutaneous transhepatic cholangiography (PTC) carries a higher operational risk. Cholangiography is considered by all to be the gold standard not only in establishing the diagnosis but also in allowing therapeutic intervention in the same setting. ${ }^{51,52}$ ERCP has the advantage over PTC and is the first modality of choice as it is not only more physiological but also less invasive. PTC is most often reserved for patients in whom ERCP is unsuccessful and in patients with Roux-en-Y hepaticojejunostomy or choledochojejunostomy. However, newer approaches using the variable stiffness colonoscope, double balloon enteroscope, single balloon enteroscope, and spiral overtube have been made it possible to reach this difficult area. ${ }^{1933-56}$ The characteristic ERCP findings in NAS consist of mucosal abnormalities, narrowing, and prestenotic dilatation, whereas the findings in AS include a thin, short, localized, isolated narrowing in the area of the biliary anastomosis (Fig. 1).

\section{MANAGEMENT}

Historically, the management of post-orthotopic liver transplantation biliary strictures consisted of surgical reconstruction in the form of Roux-en-Y hepaticojejunostomy. However, the past 2 decades have seen tremendous growth in the evolution of endoscopic techniques that they are now considered the treatment of choice for biliary strictures. ${ }^{57-60}$

Percutaneous therapy, although it has a success rate of $40 \%$ to $85 \%$ is still considered a second-line option because of the invasive nature of procedure and the associated complications of hemorrhage, bile leaks and significant morbidity. ${ }^{61}$ Surgical revision is now reserved for patients who have failed the preceding measures, and retransplantation is the final option when all else fails.

\section{NAS}

Management of patients with NAS is difficult, and any generalized treatment recommendations are difficult to make. Accumulation of biliary sludge and casts renders therapy particularly difficult because of rapid stent occlusion. Treatment of NAS did not result in significant long-term improvement of liver chemistries. It does not appear that the poor response of nonanastomotic treatment to treatment varies with etiology. ${ }^{37}$ Most importantly, NAS resulted in significantly increased graft loss.
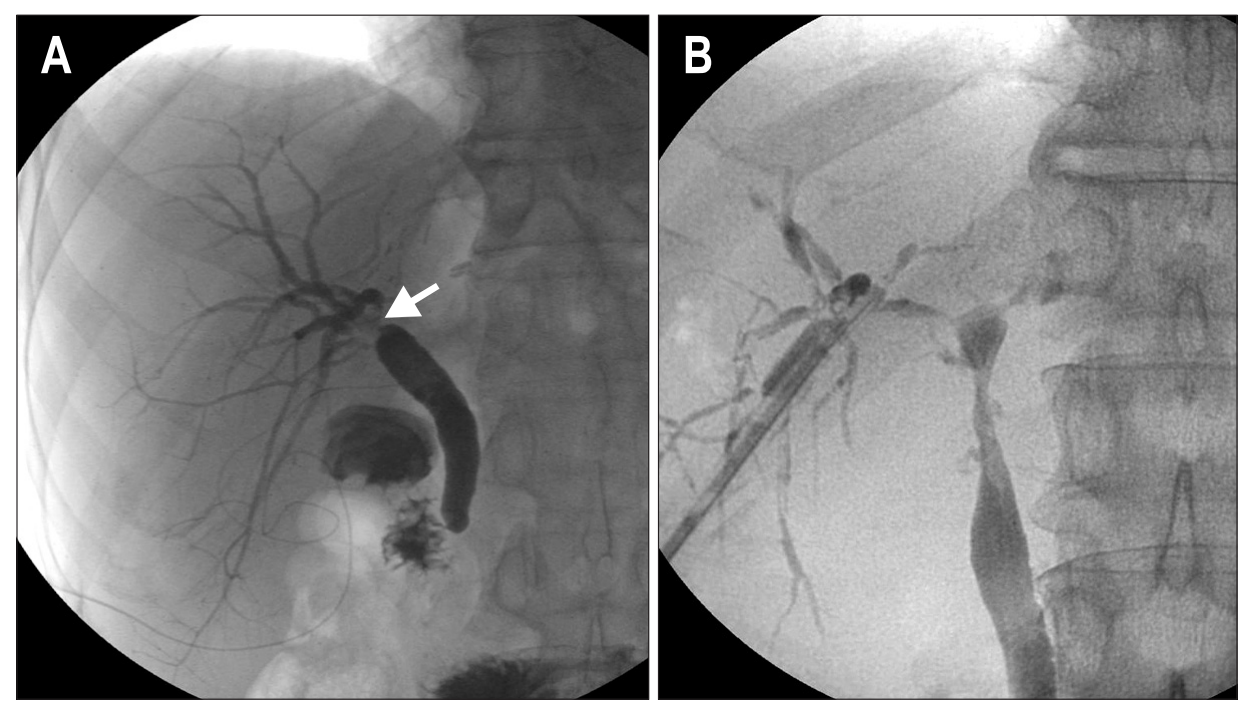

Fig. 1. Cholangiogram of an anastomotic stricture and a non-anastomotic stricture. (A) Short localized anastomotic stricture (arrow). (B) A long nonanastomotic stricture extending proximally from the anastomosis site. 
NAS are more resistant to endoscopic treatment, the results of endoscopic approaches have been particularly disappointing in the context of NAS in LDLT. The average success rate varies from $25 \%$ to $33 \%,{ }^{32,62,63}$ which is way below the $60 \%$ success rate seen with NAS in DDLT.

Endoscopic therapy of non-anastomotic strictures typically consists of extraction of the biliary sludge and casts and balloon dilation of all accessible strictures followed by placement of plastic stents with replacement every 3 month. ${ }^{37}$ However, balloon dilation of all stricture is not feasible and rapid stent clogging is frequently occurred when managing NAS. Therefore, patients with NAS may required early retransplantation, endoscopic therapy appears to play a more prominent role as a bridge to liver retransplantation. ${ }^{14,64}$

\section{AS}

The conventional method of endoscopic treatment consists of identification of the opening of the stricture followed by cannulation by the guidewire, balloon dilatation of the stricture, and subsequent placement of plastic stents.

Balloon dilation alone without stent placement is only successful in approximately $40 \%$ of cases. ${ }^{60}$ However, Balloon dilation with additional stent placement appears to be more successful with a durable outcome in $75 \%$ of patients with anastomotic strictures. ${ }^{60,65}$ The stents are generally replaced by larger stents every 3 month to prevent the complication of clogging, cholangitis, or stone formation. ${ }^{59,60,66}$ Dual or multiple stents, by providing greater dilatation, have shown better results than single stents. ${ }^{20,60}$ Placement of not one, but multiple sideby-side plastic stents further increases successful outcomes in $80 \%$ to $90 \%$ of patients. ${ }^{59,67,68}$ In some patients, a transient narrowing at a duct to duct connection appear within the first 30 to 60 days after transplantation, due to postoperative edema and inflammation. This type of stricture responds well to balloon
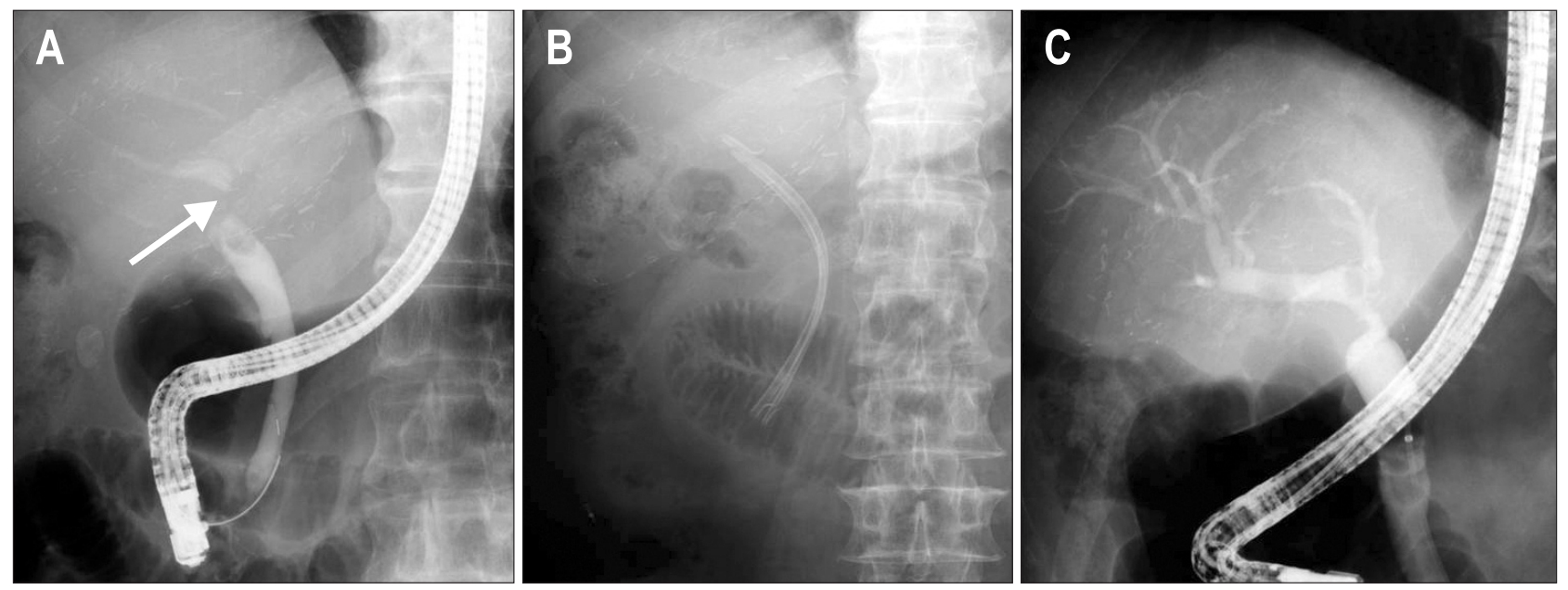

Fig. 2. A case of anastomotic stricture in a living donor liver transplantation. (A) Retrograde cholangiogram showing a biliary stricture at the anastomotic site (arrow). (B) Insertion of two straight plastic stents across the anterior duct. (C) Six-month follow-up cholangiogram showing resolution of the stricture.
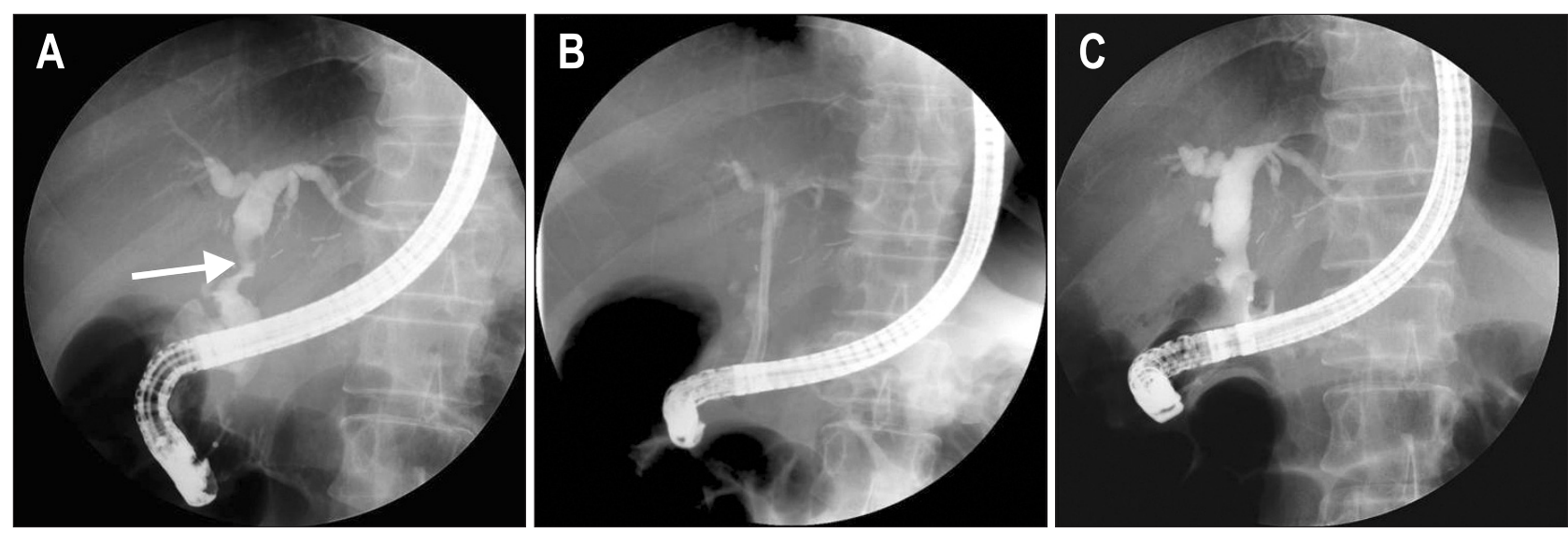

Fig. 3. Case of anastomotic stricture in a deceased donor liver transplantation (DDLT). (A) A biliary stricture is shown in the anastomosis site following the DDLT (arrow). (B) Two straight plastic stents were inserted through an anastomosis stricture. (C) The biliary stricture was resolved after 3 months. 
dilatation and temporary stent placement. ${ }^{42}$ Most patients with anastomotic strictures require ongoing ERCP sessions every 3 month with balloon dilation of 6 to $10 \mathrm{~mm}$ and multiple stents of 7 Fr to 10 Fr repeated for 12 to 24 months. ${ }^{42,59,68}$ An increasing number of stents can be used at each session to achieve a maximum diameter. The treatment is usually completed in 1 year with an average of 3 to 4 stent exchange sessions. ${ }^{18,21,59,66,69}$ Figs 2 and 3 illustrate the cholangiographic appearances of AS before and after endoscopic treatment in living and DDLT.

The overall long-term success rate of endoscopic treatment for AS associated with DDLT is in the range of 70\% to 100\%..$^{18,20,21,57,59,66,69-71}$ However, endoscopic treatment success rates in AS after LDLT appears significantly less than AS for DDLT at 37\% to 71\% (Tables 1 and 2). ${ }^{6272,73}$ When AS are treated appropriately, the long-term results in terms of patient and graft survival are equivalent to those for matched controls without AS. ${ }^{18,57,66,74}$ A protocol of accelerated dilation every 2 week, and a shortened stenting period of an average of 3.6 months, showed some encouraging results with a high $87 \%$ success rate. $^{68}$

In patients with duct to duct anastomosis, endoscopic management is hence first line, and it appears that while repeat endoscopic treatment is needed, shorter intervals in between treatments may ultimately reduce the time needed for successful long term outcomes. Despite of limited data, there is some experience in temporary placement of covered self-expanding metal stents to reduce the need for repeated stent exchanges but long term results not identified. In the few situations when endoscopic access to the AS is not obtainable, as in Roux-en-Y reconstructions, another option could be considered. A com-

Table 1. Results of Endoscopic Therapy of Post-Transplant Biliary Anastomotic Stricture in Transplants from a Deceased Donor: A Review of the Literature

\begin{tabular}{|c|c|c|c|c|c|c|c|c|c|}
\hline Author & Patients & $\begin{array}{l}\text { Interval } \\
\text { LTx first } \\
\text { ERC, mo }\end{array}$ & $\begin{array}{c}\text { No. of } \\
\text { interventions }\end{array}$ & $\begin{array}{l}\text { Success rate of } \\
\text { endoscopic } \\
\text { treatment, } \%\end{array}$ & $\begin{array}{l}\text { Treatment } \\
\text { modality }\end{array}$ & $\begin{array}{l}\text { Duration of } \\
\text { therapy, mo }\end{array}$ & $\begin{array}{c}\text { Stent-free } \\
\text { follow-up, mo }\end{array}$ & $\begin{array}{l}\text { Anastomotic } \\
\text { stricture } \\
\text { recurrence } \\
\text { rate, } \%\end{array}$ & $\begin{array}{c}\text { Complications, } \\
\%\end{array}$ \\
\hline $\begin{array}{l}\text { Rerknimitr et al. } \\
(2002)^{18}\end{array}$ & 43 & $\begin{array}{c}8.3 \\
(0.5-60)\end{array}$ & $\begin{array}{c}3.8 \\
(1-8)\end{array}$ & 100 & BD+stent & $\begin{array}{c}15.8 \\
(1.5-40)\end{array}$ & 39 (median) & 0 & 6.6 \\
\hline $\begin{array}{l}\text { Thuluvath et al. } \\
(2003)^{69}\end{array}$ & 19 & - & $\begin{array}{c}3.5 \\
(1-16)\end{array}$ & 74 & BD+stent & $3-6$ & 34 (mean) & - & 12 \\
\hline $\begin{array}{l}\text { Zoepf et al. } \\
(2006)^{65}\end{array}$ & 25 & $\begin{array}{c}5 \\
(1-33)\end{array}$ & $\begin{array}{c}4 \\
(1-11)\end{array}$ & 88 & BD+stent & $\begin{array}{c}3.5 \\
(1-24)\end{array}$ & 4 (median) & 31 & 24 \\
\hline $\begin{array}{l}\text { Holt et al. } \\
(2007)^{87}\end{array}$ & 53 & - & $\begin{array}{c}3 \\
(2-4)\end{array}$ & 69 & BD+stent & $\begin{array}{c}11.3 \\
(7-14)\end{array}$ & 18 (median) & 3 & 20.7 \\
\hline $\begin{array}{l}\text { Pasha et al. } \\
(2007)^{88}\end{array}$ & 25 & $\begin{array}{c}2 \\
(0.2-24)\end{array}$ & $\begin{array}{c}3.5 \\
(1-9)\end{array}$ & 88 & BD+stent & $\begin{array}{c}4.6 \\
(1.1-11.9)\end{array}$ & 21.5 (median) & 18 & 5 \\
\hline
\end{tabular}

LTx, liver transplantation; ERC, endoscopic retrograde cholangiography; BD, balloon dilatation.

Table 2. Results of Endoscopic Therapy of Post-Transplant Biliary Anastomic Stricture in Transplants from a Living Donor: A Review of the Literature

\begin{tabular}{|c|c|c|c|c|c|c|c|c|c|}
\hline Author & Patients & $\begin{array}{l}\text { Interval } \\
\text { LTx first } \\
\text { ERC, mo }\end{array}$ & $\begin{array}{c}\text { No. of } \\
\text { interventions }\end{array}$ & $\begin{array}{l}\text { Success rate of } \\
\text { endoscopic } \\
\text { treatment, \% }\end{array}$ & $\begin{array}{l}\text { Treatment } \\
\text { modality }\end{array}$ & $\begin{array}{l}\text { Duration of } \\
\text { therapy, mo }\end{array}$ & $\begin{array}{c}\text { Stent-free } \\
\text { follow-up, mo }\end{array}$ & $\begin{array}{l}\text { Anastomotic } \\
\text { stricture } \\
\text { recurrence } \\
\text { rate, } \%\end{array}$ & $\begin{array}{c}\text { Complications, } \\
\%\end{array}$ \\
\hline $\begin{array}{l}\text { Tsujino et al. } \\
(2006)^{62}\end{array}$ & 17 & $\begin{array}{c}5.9 \\
(1.3-12.2)\end{array}$ & $\begin{array}{c}4.1 \\
(2-8)\end{array}$ & 71 & $\mathrm{BD}_{ \pm}$stent & - & - & - & - \\
\hline $\begin{array}{l}\text { Kim et al. } \\
(2009)^{72}\end{array}$ & 60 & - & $\begin{array}{c}2 \\
(1-6)\end{array}$ & 63 & BD+stent & - & 7.9 (1.0-27.3) & 13 & 32 \\
\hline $\begin{array}{l}\text { Kato et al. } \\
(2009)^{89}\end{array}$ & 41 & $\begin{array}{c}2.8 \\
(0.7-14)\end{array}$ & $\begin{array}{c}4 \\
(1-11)\end{array}$ & 51 & $\mathrm{BD}_{ \pm}$stent & $\begin{array}{c}16.6 \\
(0.7-39.6)\end{array}$ & - & - & 19 \\
\hline $\begin{array}{l}\text { Seo et al. } \\
(2009)^{90}\end{array}$ & 68 & 8.6 & $\begin{array}{c}2.3 \\
(1.6-3.0)\end{array}$ & 64.5 & BD+stent & $\begin{array}{c}6.8 \\
(3.9-9.7)\end{array}$ & 12 (median) & 30 & 20.2 \\
\hline $\begin{array}{l}\text { Chang et al. } \\
(2010)^{17}\end{array}$ & 113 & $\begin{array}{c}6 \\
(1-71)\end{array}$ & $\begin{array}{c}3.2 \\
(1-11)\end{array}$ & 26.5 & BD+stent & - & 22 (median) & - & $\begin{array}{c}10.6 \\
\text { (immediate) } \\
29.2 \text { (late) }\end{array}$ \\
\hline $\begin{array}{l}\text { Kim et al. } \\
(2011)^{73}\end{array}$ & 147 & 5.6 & $\begin{array}{c}6.3 \\
(2.9-9.7)\end{array}$ & 36.9 & $\mathrm{BD}_{ \pm}$stent & $\begin{array}{c}12.7 \\
(3.2-22.2)\end{array}$ & 21.1 (mean) & 11.5 & 7.2 \\
\hline
\end{tabular}

LTx, liver transplantation; ERC, endoscopic retrograde cholangiography; BD, balloon dilatation. 
bined approach where access to the biliary tree is obtained via a percutaneous transhepatic route followed by "rendezvous" endoscopy. ${ }^{54,75}$ The use of percutaneous transhepatic drainage achieves success rates of 50\% to 75\%. ${ }^{76-79}$ Surgical revision and biliary reconstruction with the formation of a hepaticojejunostomy is indicated when endoscopic or percutaneous treatment fails.

\section{ENDOSCOPY PROTOCOL}

Endoscopic interventions were performed with duodenoscope after overnight fasting. After selective bile duct cannulation, anastomotic stricture could be detected as a dominant narrowing at the anastomotic site, without effective passage of contrast material, as identified by cholangiography. If the guidewire (0.025 or 0.035 inch) pass into the intrahepatic duct proximal to the site of the stricture, endoscopic sphincterotomy or endoscopic papillary balloon dilation was performed to allow placement of stent.
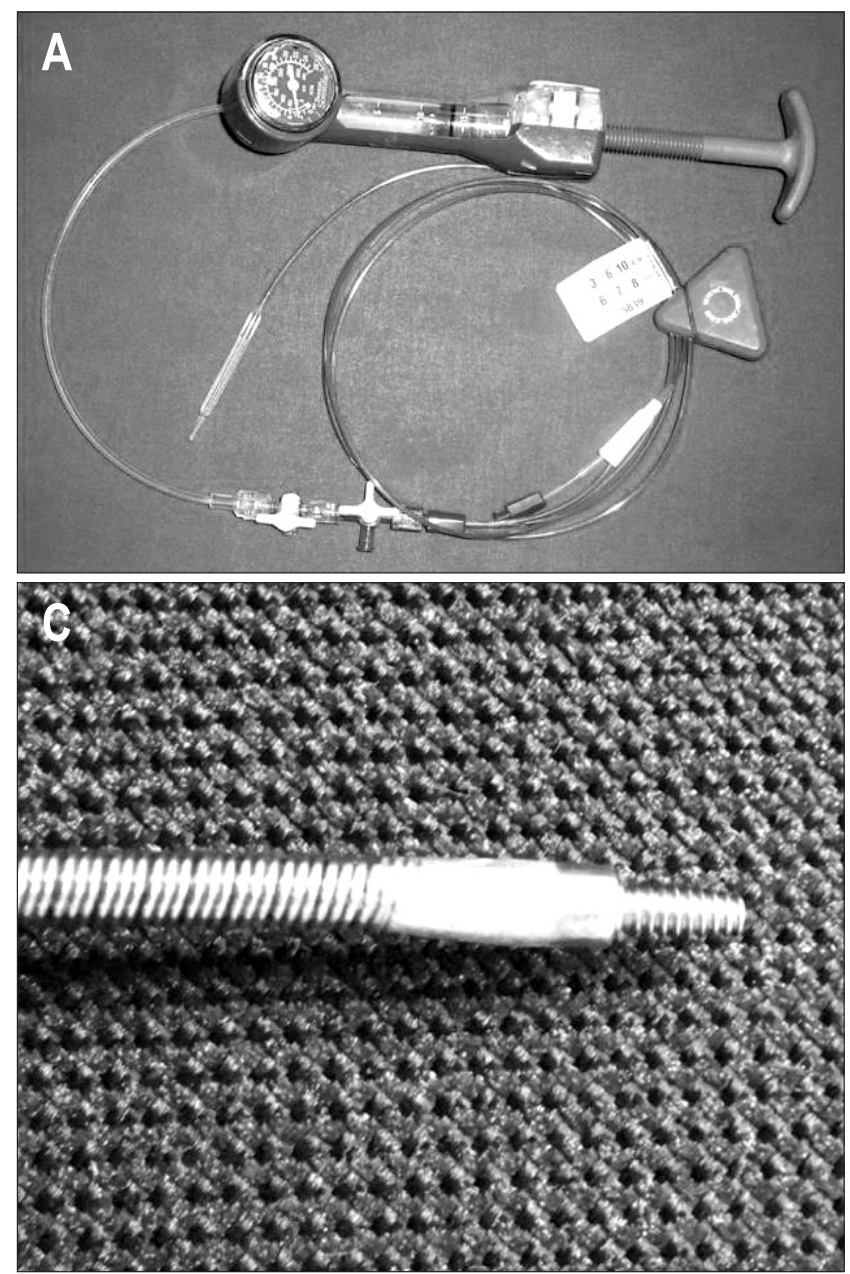

The anastomotic stricture was then dilated by using high pressure pneumatic balloons that ranged in size from 4 to $10 \mathrm{~mm}$ for 30 to 60 seconds. The Soehendra biliary dilation catheter or Soehendra stent retriever (Wilson-Cook Medical GI Endoscopy, Winston-Salem, NC, USA) was sometimes used to dilate the stricture site. A 7 to $10 \mathrm{Fr}$ straight or pigtail plastic stent was inserted after balloon dilatation (Fig. 4).

According to the characteristics of the stricture, including its location, severity of tightness, and angulation, we decided the number, size and form of the stents. For example, if an angulation was present near the stricture site and straightening and migration of the stent was anticipated, a double pig-tail stent was regarded as adequate. If the guidewire could not be passed through the stricture site or minimal narrowing at the anastomosis site that did not impede the flow of contrast material, the percutaneous transhepatic approach was used after the nasobiliary tube was placed distal to the stricture site.

After the initial endoscopic session, ERCP was scheduled electively at intervals of 2 to 3 months for evaluation of the
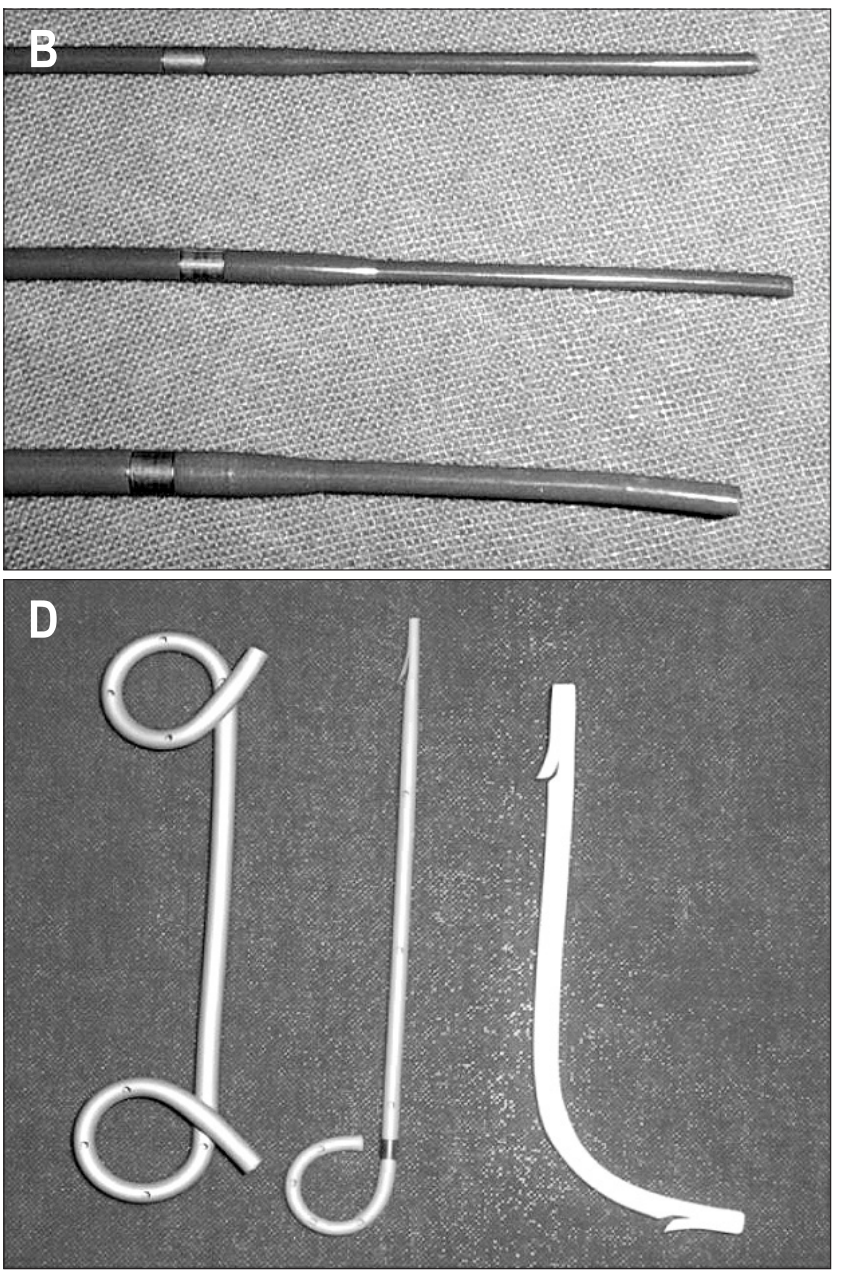

Fig. 4. Instruments used for biliary dilatation and stenting. (A) Controlled Radial Expansion (CRE) wire-guided balloon dilatation catheter (Boston Scientific Microvasive). (B) The tips of the Soehendra ${ }^{\circledR}$ biliary dilatation catheter and (C) a Soehendra ${ }^{\circledR}$ stent retriever. (D) From left to right, a double pig-tail stent (Solus double pigtail stent), a single pig-tail stent (Zimmon ${ }^{\circledR}$ pancreatic stent) and a straight plastic (Cotton-Leung ${ }^{\circledR}$ Amsterdam style biliary stent) stent (all produced by Wilson-Cook Medical GI endoscopy). 


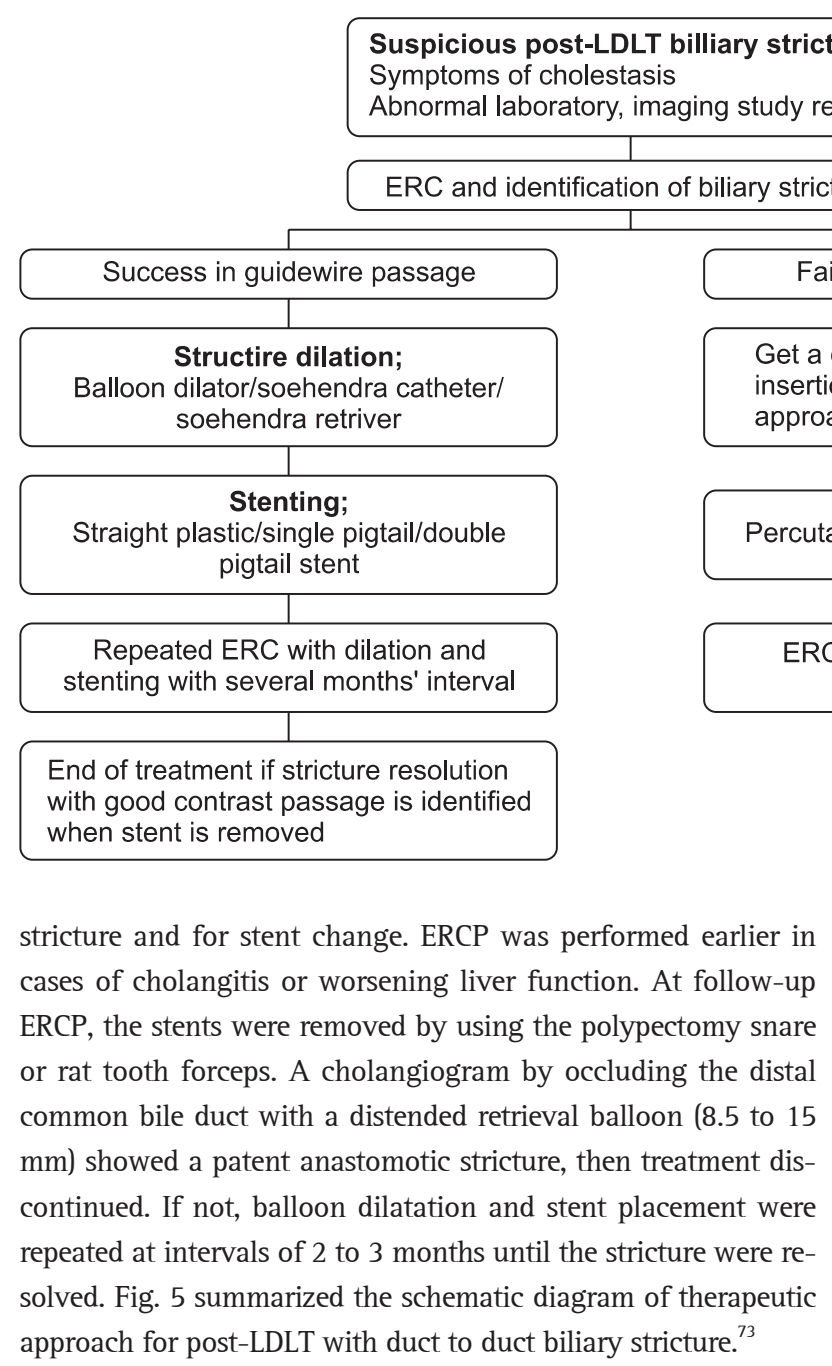

\section{FUTURE DIRECTIONS}

Use of new intraductal endoscopy technologies such as the SpyGlass direct visualization system (Boston Scientific, Natick, MA, USA), which allows visualization of the inner wall of the biliary tree and can act as the guidance system for passage of the guidewire through a tight stricture, has shown some early promise in this area. ${ }^{61,80-82}$

New types of balloons and stents will have significant role in improvement of management of biliary stricture. Preliminary evidence shows that peripheral cutting balloons may be more effective in benign biliary stricture not responsive to standard measures. ${ }^{83}$ Metal stents have been employed in an effort to reduce stricture recurrence and maintain duct patency. Traditional open-mesh metal stents are associated with occlusion, stone formation, and lack of permanency, epithelial hyperplasia. ${ }^{84}$ These disadvantages of metal stents have traditionally limited their use in benign biliary strictures. The drawbacks of uncovered metal stents have led to the use of covered metal stents, with the potential benefit that these stents can be removed. However, the use of covered metal stents needs further evaluation to de- termine their therapeutic effectiveness. Self-expanding stents made of bioabsorbable material may offer several advantages compared to the plastic and self-expanding metal stents. ${ }^{85,86}$ Studies in porcine models show that these stents offer improved patency because of their large diameter, lower biofilm accumulation and reduced incidence of bile duct proliferative changes. Furthermore, patients do not have to undergo additional procedures to remove the stents. Bioabsorbable stents can be impregnated with pharmaceutical compounds, such as antimicrobial and antineoplastic agents. However, these stents remains investigational at the present time.

\section{CONCLUSIONS}

The landscape related to biliary complications after liver transplantation has changed rather rapidly in the past 2 decades. The conventional management of these conditions in the past was mainly surgical. However, therapeutic endoscopy plays an important role in the treatment of post-liver transplant anastomotic strictures. At present, the preferred endoscopic approach is repeated aggressive dilation of the stricture and insertion of multiple plastic stents, particularly anastomotic stricture. Percutaneous and surgical modalities are now reserved for patients in whom endoscopic treatment fails and for those with multiple inaccessible intrahepatic strictures or Roux-en-Y anastomoses. With advances of small bowel endoscopy, Roux-en-Y anastomosis site is accessible to endoscopic treatments. Fully covered metal stents or bioabsorbable stents may provide superior results and deserve further investigation. The area of therapeutic endoscopy will continue to evolve and offer opportunities for innovative new techniques in orthotopic liver transplantation patient related to biliary stricture. 


\section{REFERENCES}

1. Ahmed A, Keeffe EB. Current indications and contraindications for liver transplantation. Clin Liver Dis 2007;11:227-247.

2. Murray KF, Carithers RL Jr; AASLD. AASLD practice guidelines: evaluation of the patient for liver transplantation. Hepatology 2005;41:1407-1432.

3. Consensus Conference: Indications for Liver Transplantation, January 19 and 20, 2005, Lyon-Palais Des Congrès: text of recommendations (long version). Liver Transpl 2006;12:998-1011.

4. Jain A, Reyes J, Kashyap R, et al. Long-term survival after liver transplantation in 4,000 consecutive patients at a single center. Ann Surg 2000;232:490-500.

5. Abbasoglu 0, Levy MF, Brkic BB, et al. Ten years of liver transplantation: an evolving understanding of late graft loss. Transplantation 1997;64:1801-1807.

6. Asfar S, Metrakos P, Fryer J, et al. An analysis of late deaths after liver transplantation. Transplantation 1996;61:1377-1381.

7. Gordon RD, Fung J, Tzakis AG, et al. Liver transplantation at the University of Pittsburgh, 1984 to 1990. Clin Transpl 1991:105117.

8. Koneru B, Sterling MJ, Bahramipour PF. Bile duct strictures after liver transplantation: a changing landscape of the Achilles' heel. Liver Transpl 2006;12:702-704.

9. Greif F, Bronsther OL, Van Thiel DH, et al. The incidence, timing, and management of biliary tract complications after orthotopic liver transplantation. Ann Surg 1994;219:40-45.

10. Stratta RJ, Wood RP, Langnas AN, et al. Diagnosis and treatment of biliary tract complications after orthotopic liver transplantation. Surgery 1989;106:675-683.

11. Colonna JO 2nd, Shaked A, Gomes AS, et al. Biliary strictures complicating liver transplantation. Incidence, pathogenesis, management, and outcome. Ann Surg 1992;216:344-350.

12. Brown RS Jr. Live donors in liver transplantation. Gastroenterology 2008;134:1802-1813.

13. Noack K, Bronk SF, Kato A, Gores GJ. The greater vulnerability of bile duct cells to reoxygenation injury than to anoxia. Implications for the pathogenesis of biliary strictures after liver transplantation. Transplantation 1993;56:495-500.

14. Tung BY, Kimmey MB. Biliary complications of orthotopic liver transplantation. Dig Dis 1999;17:133-144.

15. Porayko MK, Kondo M, Steers JL. Liver transplantation: late complications of the biliary tract and their management. Semin Liver Dis 1995;15:139-155.

16. Testa G, Malagò M, Broelseh CE. Complications of biliary tract in liver transplantation. World J Surg 2001;25:1296-1299.

17. Chang JH, Lee IS, Choi JY, et al. Biliary stricture after adult rightlobe living-donor liver transplantation with duct-to-duct anastomosis: long-term outcome and its related factors after endoscopic treatment. Gut Liver 2010;4:226-233.

18. Rerknimitr R, Sherman S, Fogel EL, et al. Biliary tract complications after orthotopic liver transplantation with choledochocho- ledochostomy anastomosis: endoscopic findings and results of therapy. Gastrointest Endosc 2002;55:224-231.

19. Thethy S, Thomson BN, Pleass $\mathrm{H}$, et al. Management of biliary tract complications after orthotopic liver transplantation. Clin Transplant 2004;18:647-653.

20. Graziadei IW, Schwaighofer H, Koch R, et al. Long-term outcome of endoscopic treatment of biliary strictures after liver transplantation. Liver Transpl 2006;12:718-725.

21. Bourgeois N, Deviére J, Yeaton P, et al. Diagnostic and therapeutic endoscopic retrograde cholangiography after liver transplantation. Gastrointest Endosc 1995;42:527-534.

22. Park JS, Kim MH, Lee SK, et al. Efficacy of endoscopic and percutaneous treatments for biliary complications after cadaveric and living donor liver transplantation. Gastrointest Endosc 2003;57:78-85.

23. Verdonk RC, Buis CI, Porte RJ, et al. Anastomotic biliary strictures after liver transplantation: causes and consequences. Liver Transpl 2006;12:726-735.

24. Ostroff JW. Post-transplant biliary problems. Gastrointest Endosc Clin N Am 2001;11:163-183.

25. Jagannath S, Kalloo AN. Biliary complications after liver transplantation. Curr Treat Options Gastroenterol 2002;5:101-112.

26. O'Connor TP, Lewis WD, Jenkins RL. Biliary tract complications after liver transplantation. Arch Surg 1995;130:312-317.

27. Rouch DA, Emond JC, Thistlethwaite JR Jr, Mayes JT, Broelsch CE. Choledochocholedochostomy without a $\mathrm{T}$ tube or internal stent in transplantation of the liver. Surg Gynecol Obstet 1990;170:239244

28. Rolles K, Dawson K, Novell R, Hayter B, Davidson B, Burroughs A. Biliary anastomosis after liver transplantation does not benefit from T tube splintage. Transplantation 1994;57:402-404.

29. Vougas V, Rela M, Gane E, et al. A prospective randomised trial of bile duct reconstruction at liver transplantation: $\mathrm{T}$ tube or no $\mathrm{T}$ tube? Transpl Int 1996;9:392-395.

30. Nuño J, Vicente E, Turrión VS, et al. Biliary tract reconstruction after liver transplantation: with or without T-tube? Transplant Proc 1997;29:564-565.

31. Sampietro R, Goffette P, Danse E, et al. Extension of the adult hepatic allograft pool using split liver transplantation. Acta Gastroenterol Belg 2005;68:369-375.

32. Yazumi S, Yoshimoto T, Hisatsune H, et al. Endoscopic treatment of biliary complications after right-lobe living-donor liver transplantation with duct-to-duct biliary anastomosis. J Hepatobiliary Pancreat Surg 2006;13:502-510.

33. Stapleton GN, Hickman R, Terblanche J. Blood supply of the right and left hepatic ducts. Br J Surg 1998;85:202-207.

34. Shokouh-Amiri MH, Grewal HP, Vera SR, Stratta RJ, Bagous W, Gaber AO. Duct-to-duct biliary reconstruction in right lobe adult living donor liver transplantation. J Am Coll Surg 2001;192:798803.

35. Spada M, Cescon M, Aluffi A, et al. Use of extended right grafts from in situ split livers in adult liver transplantation: a comparison 
with whole-liver transplants. Transplant Proc 2005;37:1164-1166.

36. Moench C, Moench K, Lohse AW, Thies J, Otto G. Prevention of ischemic-type biliary lesions by arterial back-table pressure perfusion. Liver Transpl 2003;9:285-289.

37. Guichelaar MM, Benson JT, Malinchoc M, Krom RA, Wiesner RH, Charlton MR. Risk factors for and clinical course of non-anastomotic biliary strictures after liver transplantation. Am J Transplant 2003;3:885-890.

38. Sankary HN, Rypins EB, Waxman K, et al. Effects of portacaval shunt and hepatic artery ligation on liver surface oxygen tension and effective hepatic blood flow. J Surg Res 1987;42:7-9.

39. Verdonk RC, Buis CI, van der Jagt EJ, et al. Nonanastomotic biliary strictures after liver transplantation, part 2: management, outcome, and risk factors for disease progression. Liver Transpl 2007;13:725-732.

40. Verdonk RC, Buis CI, Porte RJ, Haagsma EB. Biliary complications after liver transplantation: a review. Scand J Gastroenterol Suppl 2006;(243):89-101.

41. Pascher A, Neuhaus P. Biliary complications after deceased-donor orthotopic liver transplantation. J Hepatobiliary Pancreat Surg 2006;13:487-496.

42. Thuluvath PJ, Pfau PR, Kimmey MB, Ginsberg GG. Biliary complications after liver transplantation: the role of endoscopy. Endoscopy 2005;37:857-863.

43. Venu M, Brown RD, Lepe R, et al. Laboratory diagnosis and nonoperative management of biliary complications in living donor liver transplant patients. J Clin Gastroenterol 2007;41:501-506.

44. Sharma S, Gurakar A, Camci C, Jabbour N. Avoiding pitfalls: what an endoscopist should know in liver transplantation--part II. Dig Dis Sci 2009;54:1386-1402.

45. St Peter S, Rodriquez-Davalos MI, Rodriguez-Luna HM, Harrison EM, Moss AA, Mulligan DC. Significance of proximal biliary dilatation in patients with anastomotic strictures after liver transplantation. Dig Dis Sci 2004;49:1207-1211.

46. Macfarlane B, Davidson B, Dooley JS, et al. Endoscopic retrograde cholangiography in the diagnosis and endoscopic management of biliary complications after liver transplantation. Eur J Gastroenterol Hepatol 1996;8:1003-1006.

47. Schwarzenberg SJ, Sharp HL, Payne WD, et al. Biliary stricture in living-related donor liver transplantation: management with balloon dilation. Pediatr Transplant 2002;6:132-135.

48. Fulcher AS, Turner MA. Orthotopic liver transplantation: evaluation with MR cholangiography. Radiology 1999;211:715-722.

49. Linhares MM, Gonzalez AM, Goldman SM, et al. Magnetic resonance cholangiography in the diagnosis of biliary complications after orthotopic liver transplantation. Transplant Proc 2004;36:947-948.

50. Meersschaut V, Mortelé KJ, Troisi R, et al. Value of MR cholangiography in the evaluation of postoperative biliary complications following orthotopic liver transplantation. Eur Radiol 2000;10:1576-1581.

51. Hussaini SH, Sheridan MB, Davies M. The predictive value of transabdominal ultrasonography in the diagnosis of biliary tract complications after orthotopic liver transplantation. Gut 1999;45:900-903.

52. Kurzawinski TR, Selves L, Farouk M, et al. Prospective study of hepatobiliary scintigraphy and endoscopic cholangiography for the detection of early biliary complications after orthotopic liver transplantation. Br J Surg 1997;84:620-623.

53. Chahal P, Baron TH, Poterucha JJ, Rosen CB. Endoscopic retrograde cholangiography in post-orthotopic liver transplant population with Roux-en-Y biliary reconstruction. Liver Transpl 2007;13:1168-1173.

54. Kawano Y, Mizuta K, Hishikawa S, et al. Rendezvous penetration method using double-balloon endoscopy for complete anastomosis obstruction of hepaticojejunostomy after pediatric living donor liver transplantation. Liver Transpl 2008;14:385-387.

55. Koornstra JJ, Fry L, Mönkemüller K. ERCP with the balloonassisted enteroscopy technique: a systematic review. Dig Dis 2008;26:324-329.

56. Mönkemüller K, Fry LC, Bellutti M, Neumann H, Malfertheiner P. ERCP using single-balloon instead of double-balloon enteroscopy in patients with Roux-en-Y anastomosis. Endoscopy 2008;40 Suppl 2:E19-E20.

57. Mahajani RV, Cotler SJ, Uzer MF. Efficacy of endoscopic management of anastomotic biliary strictures after hepatic transplantation. Endoscopy 2000;32:943-949.

58. Rossi AF, Grosso C, Zanasi G, et al. Long-term efficacy of endoscopic stenting in patients with stricture of the biliary anastomosis after orthotopic liver transplantation. Endoscopy 1998;30:360366.

59. Morelli J, Mulcahy HE, Willner IR, Cunningham JT, Draganov P. Long-term outcomes for patients with post-liver transplant anastomotic biliary strictures treated by endoscopic stent placement. Gastrointest Endosc 2003;58:374-379.

60. Schwartz DA, Petersen BT, Poterucha JJ, Gostout CJ. Endoscopic therapy of anastomotic bile duct strictures occurring after liver transplantation. Gastrointest Endosc 2000;51:169-174.

61. Sharma S, Gurakar A, Jabbour N. Biliary strictures following liver transplantation: past, present and preventive strategies. Liver Transpl 2008;14:759-769.

62. Tsujino T, Isayama H, Sugawara $Y$, et al. Endoscopic management of biliary complications after adult living donor liver transplantation. Am J Gastroenterol 2006;101:2230-2236.

63. Tada S, Yazumi S, Chiba T. Endoscopic management is an accepted first-line therapy for biliary complications after adult living donor liver transplantation. Am J Gastroenterol 2007;102:1331.

64. Zajko AB, Campbell WL, Logsdon GA, et al. Cholangiographic findings in hepatic artery occlusion after liver transplantation. AJR Am J Roentgenol 1987;149:485-489.

65. Zoepf T, Maldonado-Lopez EJ, Hilgard P, et al. Balloon dilatation vs. balloon dilatation plus bile duct endoprostheses for treatment of anastomotic biliary strictures after liver transplantation. Liver Transpl 2006;12:88-94. 
66. Rizk RS, McVicar JP, Emond MJ, et al. Endoscopic management of biliary strictures in liver transplant recipients: effect on patient and graft survival. Gastrointest Endosc 1998;47:128-135.

67. Costamagna G, Pandolfi M, Mutignani M, Spada C, Perri V. Longterm results of endoscopic management of postoperative bile duct strictures with increasing numbers of stents. Gastrointest Endosc 2001;54:162-168.

68. Morelli G, Fazel A, Judah J, Pan JJ, Forsmark C, Draganov P. Rapid-sequence endoscopic management of posttransplant anastomotic biliary strictures. Gastrointest Endosc 2008;67:879-885.

69. Thuluvath PJ, Atassi T, Lee J. An endoscopic approach to biliary complications following orthotopic liver transplantation. Liver Int 2003;23:156-162.

70. Chahin NJ, De Carlis L, Slim A0, et al. Long-term efficacy of endoscopic stenting in patients with stricture of the biliary anastomosis after orthotopic liver transplantation. Transplant Proc 2001;33:2738-2740.

71. Alazmi WM, Fogel EL, Watkins JL, et al. Recurrence rate of anastomotic biliary strictures in patients who have had previous successful endoscopic therapy for anastomotic narrowing after orthotopic liver transplantation. Endoscopy 2006;38:571-574.

72. Kim ES, Lee BJ, Won JY, Choi JY, Lee DK. Percutaneous transhepatic biliary drainage may serve as a successful rescue procedure in failed cases of endoscopic therapy for a post-living donor liver transplantation biliary stricture. Gastrointest Endosc 2009;69:3846.

73. Kim TH, Lee SK, Han JH, et al. The role of endoscopic retrograde cholangiography for biliary stricture after adult living donor liver transplantation: technical aspect and outcome. Scand J Gastroenterol 2011;46:188-196.

74. Pfau PR, Kochman ML, Lewis JD, et al. Endoscopic management of postoperative biliary complications in orthotopic liver transplantation. Gastrointest Endosc 2000;52:55-63.

75. Matlock J, Freeman ML. Endoscopic therapy of benign biliary strictures. Rev Gastroenterol Disord 2005;5:206-214.

76. Civelli EM, Meroni R, Cozzi G, et al. The role of interventional radiology in biliary complications after orthotopic liver transplantation: a single-center experience. Eur Radiol 2004;14:579-582.

77. Roumilhac D, Poyet G, Sergent G, et al. Long-term results of percutaneous management for anastomotic biliary stricture after orthotopic liver transplantation. Liver Transpl 2003;9:394-400.

78. Sung RS, Campbell DA Jr, Rudich SM, et al. Long-term follow-up of percutaneous transhepatic balloon cholangioplasty in the man- agement of biliary strictures after liver transplantation. Transplantation 2004;77:110-115.

79. Zajko AB, Sheng R, Zetti GM, Madariaga JR, Bron KM. Transhepatic balloon dilation of biliary strictures in liver transplant patients: a 10-year experience. J Vasc Interv Radiol 1995;6:79-83.

80. Chen YK, Pleskow DK. SpyGlass single-operator peroral cholangiopancreatoscopy system for the diagnosis and therapy of bileduct disorders: a clinical feasibility study (with video). Gastrointest Endosc 2007;65:832-841.

81. Judah JR, Draganov PV. Intraductal biliary and pancreatic endoscopy: an expanding scope of possibility. World J Gastroenterol 2008;14:3129-3136.

82. Wright H, Sharma S, Gurakar A, Sebastian A, Kohli V, Jabbour N. Management of biliary stricture guided by the Spyglass Direct Visualization System in a liver transplant recipient: an innovative approach. Gastrointest Endosc 2008;67:1201-1203.

83. Atar E, Bachar GN, Bartal G, et al. Use of peripheral cutting balloon in the management of resistant benign ureteral and biliary strictures. J Vasc Interv Radiol 2005;16(2 Pt 1):241-245.

84. Silvis SE, Sievert CE Jr, Vennes JA, Abeyta BK, Brennecke LH. Comparison of covered versus uncovered wire mesh stents in the canine biliary tract. Gastrointest Endosc 1994;40:17-21.

85. Ginsberg G, Cope C, Shah J, et al. In vivo evaluation of a new bioabsorbable self-expanding biliary stent. Gastrointest Endosc 2003;58:777-784.

86. Meng B, Wang J, Zhu N, Meng QY, Cui FZ, Xu YX. Study of biodegradable and self-expandable PLLA helical biliary stent in vivo and in vitro. J Mater Sci Mater Med 2006;17:611-617.

87. Holt AP, Thorburn D, Mirza D, Gunson B, Wong T, Haydon G. A prospective study of standardized nonsurgical therapy in the management of biliary anastomotic strictures complicating liver transplantation. Transplantation 2007;84:857-863.

88. Pasha SF, Harrison ME, Das A, et al. Endoscopic treatment of anastomotic biliary strictures after deceased donor liver transplantation: outcomes after maximal stent therapy. Gastrointest Endosc 2007;66:44-51.

89. Kato H, Kawamoto H, Tsutsumi K, et al. Long-term outcomes of endoscopic management for biliary strictures after living donor liver transplantation with duct-to-duct reconstruction. Transpl Int 2009;22:914-921.

90. Seo JK, Ryu JK, Lee SH, et al. Endoscopic treatment for biliary stricture after adult living donor liver transplantation. Liver Transpl 2009;15:369-380. 